Sulfur prints of transverse sections of slabs, showing segregation at the 50 and 90 -pct ingot levels. Top view is from a 29 . in. ingot and bottom is from a 22-in. ingot. Rimmed steel.

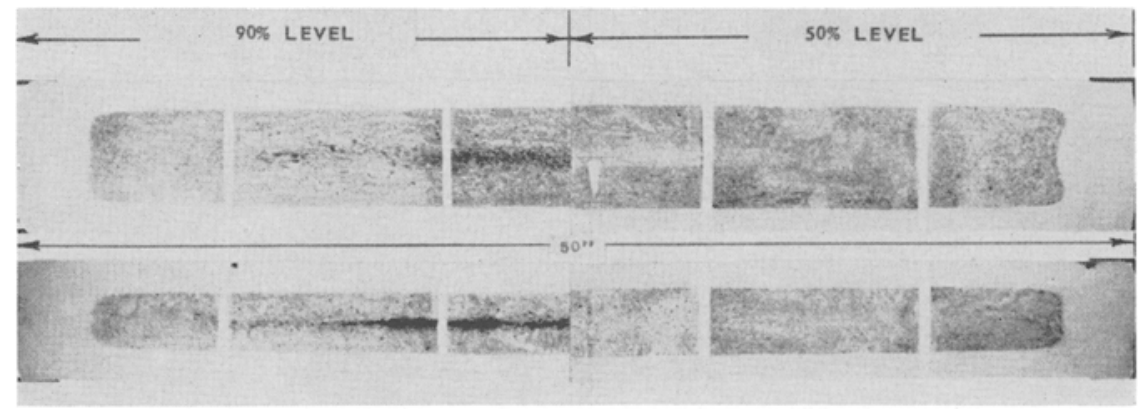

\title{
Higher Rolling Mill Output Stirs Inquiry Into Ingot Thickness
}

$\mathbf{I}^{\mathrm{N}}$

NCREASED use of high-speed, high-capacity continuous rolling techniques is causing steel men to take a searching look at means of ensuring uniform quality in large size rimmed ingots where segregation tends to be greatest. Efforts are being made to solve this problem, one of the oldest in the industry-segregation of impurities, particularly sulfur.

This review is abstracted from two recent studies on the subject, one by J. S. McNairn of Ford Motor Co., entitled Ingot Thickness and Its Effects on Drawing Quality, and the other by W. H. Mayo, S. B. Prellwitz, and M. B. Jacobs all of U. S. Steel Corp., entitled Effects of Ingot Thickness on Quality of Rimmed Steel. These were presented in their original form at the National Open Hearth Steel Conference, Cincinnati, April 1956.

Tests have been made both on slabs and sheets to determine what effect various ingot thicknesses have on the pattern of sulfur segregation. These reveal that thicker ingots have their peak segregation at a lower level, often with two or more peaks occurring instead of just one. In the resulting sheets, peaks occur only when ladle sulfur is high, as shown by the center steel analyses at right. Carbon segregation did not show any relation to ingot thickness.

Variation in the position of segregation peaks was as much as 5 pct for no apparent reason. It was, therefore, concluded that there were additional factors which may affect segregation characteristics to an equal or even greater degree than ingot thickness. Experiments to determine the nature of these factors are continuing.

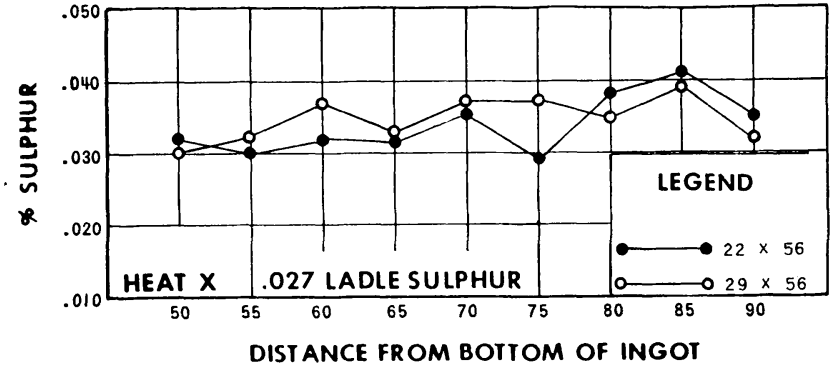

Effect of both ladle sulfur and ingot thickness on segregation in sheets is shown in the graphs above and below. Both are center sheet sulfur analyses for rimmed steel. At bottom are shown curves for high ladle sulfur ingots, with the thicker ingot having a greater peak. The top curves show that at low ladle sulfur, ingot thickness has a negligible effect on sulfur segregation in the sheets.

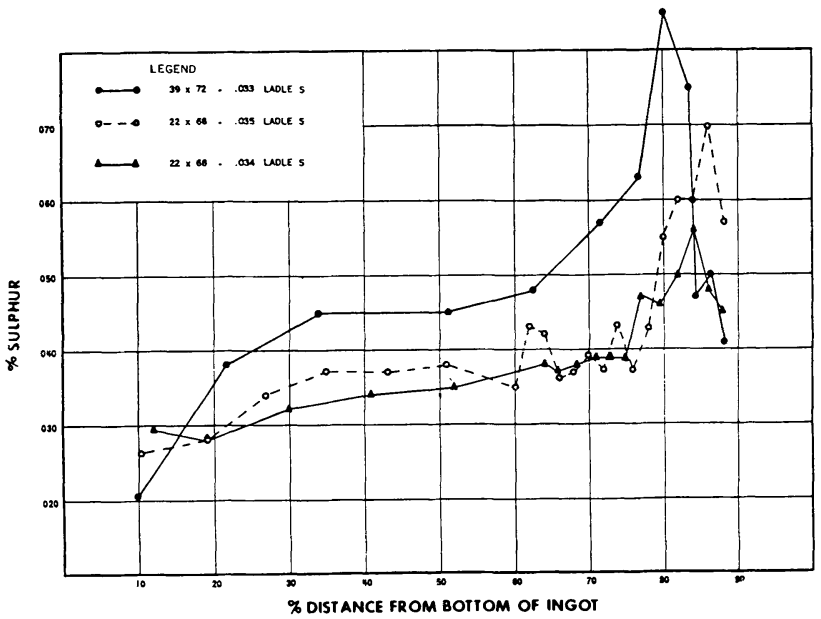

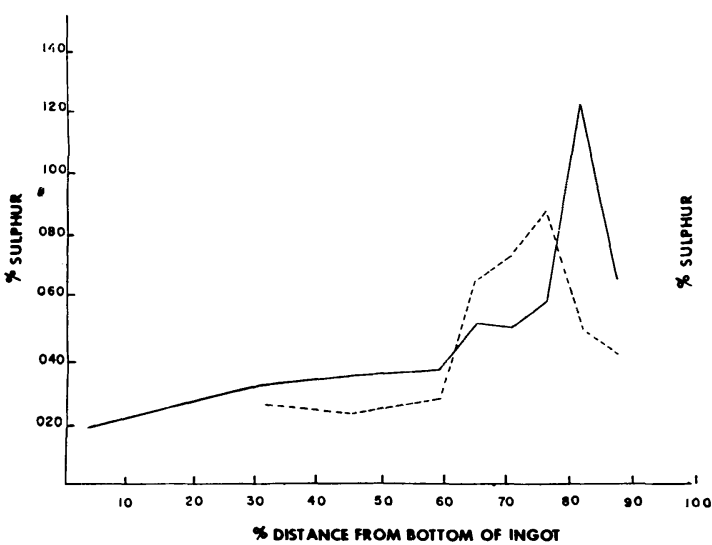

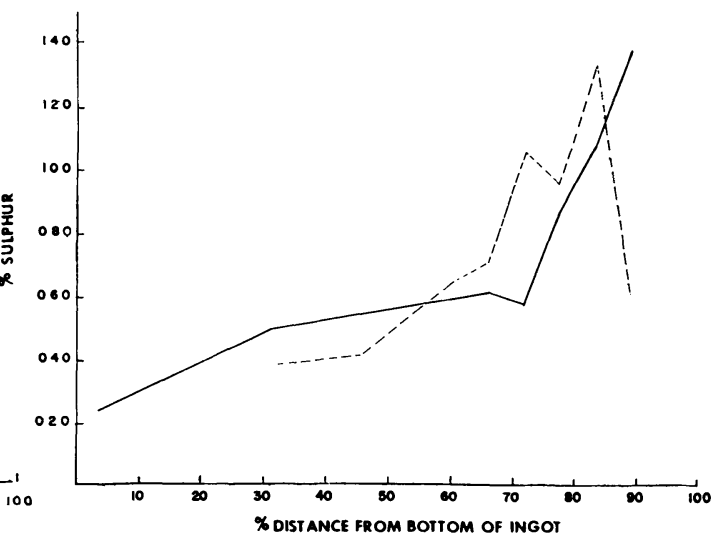

Distribution of sulfur in longitudinal section of slabs from $23 \times 57$-in. (solid line) and 29x57in. (dotted line) ingots. Left and right curves are for rimmed ingots with 0.027 and 0.035 center line ladle sulfurs, respectively. 